УДК 618.3-06: 616-092.6

DOI 10.11603/24116-4944.2019.2.10920

(C). О. Остафійчук

Івано-Франківсъкий нащіональний медичний університет

\title{
ДИНАМІКА ВОДНИХ СЕКТОРІВ У ВАГІТНИХ ЖІНОК ІЗ ПАТОЛОГІЧНИМ ГЕСТАЦІЙНИМ ЗБІЛЬШЕННЯМ МАСИ ТІЛА
}

Мета дослідження - встановити динаміку водних секторів у материнському організмі під час вагітності у жінок 3 рекомендованим та патологічним гестаційним збільшенням маси тіла (ГЗМТ).

Матеріали та методи. Обстежено 153 вагітних жінок з нормальною масою до вагітності $($ IMT $(20,3 \pm 1,5)$ кг/м²). Рекомендоване ГзМТ виявлено у 77 (50,3\%), недостатнє - у 31 (20,3 \%), а надлишкове у 45 (29,4 \%) пацієнток. Методом спектральної біоімпедансометрії (БІМ) об'єми загальної води організму (ЗВО), внутрішньоклітинної (ВКР) та позаклітинної рідини (ПКР), а також показники антропометрії, визначали в кожному триместрі.

Результати дослідження та їх обговорення. У групі жінок із рекомендованим ГЗМТ продемонстровано рівномірне зростання всіх рідинних компонентів із співвідношенням ПКР/3ВО 0,35 у всіх триместрах. При недостатньому ГЗМТ відмічено нижчий показник ЗВО порівняно з нормальною надбавкою у масі, починаючи від ранніх термінів, відсутність динаміки відсотка ПКР, стабільний об'єм ВКР та збереження ПКР/ЗВО 0,34 у всіх триместрах. Надлишкове ГЗМТ супроводжується надмірним зростанням ЗВО в третьому триместрі, значним накопиченням рідини в інтерстиціальному секторі, починаючи вже з ранніх строків, із досягненням піку в кінці вагітності. Такий патологічний перерозподіл ПКР/3ВО 0,39, 0,44 і 0,44 відповідно в кожному триместрі, порівняно з нормальним ГзМТ, є ризиком акушерських та перинатальних ускладнень, пов'язаних з гемодинамічними розладами.

Висновки. Продемонстровано доцільність використання спектральної біоімпедансометрії для моніторингу динаміки водних секторів у вагітних жінок, починаючи з першого триместру, з метою раннього виявлення надмірної затримки рідини та перерозподілу рідинних секторів, що приводить до патологічного ГЗМТ і $є$ проявом гемодинамічної дезадаптації впродовж перебігу вагітності.

Ключові слова: спектральна біоімпедансометрія; загальна вода організму; гестаційне збільшення маси тіла.

ДИНАМИКА ВОДНЫХ СЕКТОРОВ У БЕРЕМЕННЫХ ЖЕНЩИН С ПАТОЛОГИЧЕСКИМ ГЕСТАЦИОННЫМ УВЕЛИЧЕНИЕМ МАССЫ ТЕЛА

Цель исследования - установить динамику водных секторов в материнском организме во время беременности у женщин с рекомендованным и патологическим гестационным увеличением массы тела (ГУМТ).

Материалы и методы. Обследовано 153 беременных женщин с нормальным весом до беременности $($ ИМТ $(20,3 \pm 1,5)$ кг/м²). Рекомендуемое ГУМТ обнаружено у 77 (50,3 \%), недостаточное - у 31 (20,3 \%), а избыточное у 45 (29,4 \%) пациенток. Методом спектральной биоимпедансометрии (БИМ) объемы общей воды организма (ОВО), внутриклеточной (ВнуКЖ) и внеклеточной жидкости (ВнеКЖ), а также показатели антропометрии, определяли в каждом триместре.

Результаты исследования и их обсуждение. В группе женщин с рекомендованным ГУМТ продемонстрировано равномерный рост всех жидкостных секторов с соотношением ВнеКЖ/ОВО 0,35 во всех триместрах. При недостаточном ГУМТ отмечено низкий показатель ОВО по сравнению с нормальной прибавкой в весе, начиная с ранних сроков, отсутствие динамики процента ВнеКЖ, стабильный объем ВнуКЖ и сохранение ВнеКЖ/ОВО 0,34 во всех триместрах. Избыточное ГУМТ сопровождается чрезмерным ростом ОВО в третьем триместре, значительным накоплением жидкости в интерстициальном секторе, начиная уже с ранних сроков, с достижением пика в конце беременности. Такое патологическое перераспределение ВнеКЖ/ОВО 0,39, 0,44 и 0,44 соответственно в каждом триместре, по сравнению с нормальным ГУМТ, является риском акушерских и перинатальных осложнений, связанных с гемодинамическими расстройствами.

Выводы. Продемонстрировано целесообразность использования спектральной биоимпедансометрии для мониторинга динамики водных секторов у беременных женщин, начиная с первого триместра, с целью раннего выявления чрезмерной задержки жидкости и перераспределения её в жидкостных секторах, что ведет к патологическому ГУМТ и является проявлением гемодинамической дезадаптации на протяжении беременности.

Ключевые слова: спектральная биоимпедансометрия; общая вода организма; гестационное увеличение массы тела.

BODY WATER DISTRIBUTION IN PREGNANT WOMEN WITH PATHOLOGICAL GESTATION WEIGHT GAIN

The aim of the study - to assess the changes in body water compartments in pregnant women with recommended and pathological gestational weight gain (GWG).

Materials and Methods. 153 pregnant women with normal prepregnancy weight BMI $(20.3 \pm 1.5) \mathrm{kg} / \mathrm{m}^{2}$ participated. The recommended GWG was determined in 77 (50.3\%), insufficient - in 31 (20.3\%), and excessive in 45 (29.4\%) patients. The total body water (TBW), intracellular water (ICW) and extracellular water (ECW), as well as anthropometric measurements, were determined in each trimester using the bioelectrical impedance analysis.

Results and Discussion. The uniform rise of body water compartments with a relation of ECW/TBW -0.35 in all trimesters in the group of women with recommended GWG was demonstrated. Compared to the normal weight gain women, lower TBW from the early terms, absence of the dynamics of ECW \% and the stable volume of ICW, normal relation of ECW/TBW - 0.34 are in all trimesters in the case of insufficient GWG. Excessive GWG is accompanied by an excessive increase in TBW in the third trimester, a significant accumulation of fluid in the interstitial sector, from the early stages with peak at the end of pregnancy. Compared to 
normal GWG pregnant, such pathological redistribution of ECW/TBW $-0.39,0.44$ and 0.44 , respectively in each trimester, is a risk of obstetric and perinatal complications associated with hemodynamic disorders.

Conclusions. Our results show that the bio-impedance analysis can be used to monitor variants in body water volumes in pregnant women from the first trimester and detect early excessive fluid retention and redistribution of water compartments that lead to pathological GWG and illustrate a manifestation of hemodynamic maladaptation to pregnancy.

Key words: bio-impedance analysis; total body water; gestational weight gain.

встУП. Під час вагітності склад материнського організму зазнає глибоких змін з метою його адаптації до нових умов життєдіяльності й адекватного росту і розвитку плода. Жирова маса тіла (ЖМТ), безжирова маса (БЖМ), загальна вода організму (ЗВО) зростають різними шляхами і темпами, а їх вплив на результати вагітності представляє широкий інтерес в акушерській та перинатальній медицині [1]. Інститутом медицини (США, 2009) розроблено стандарти оптимального рівня гестаційного збільшення маси тіла (ГЗМТ) залежно від прегравідарного індексу маси тіла (IMT) [2]. До компонентів, що визначають найбільший вклад у ГЗМТ, належать фето-материнські структури (плід, амніон, амніотична рідина, плацента, матка), материнські жирова тканина та молочні залози, а також загальна вода організму [3] ЗВО в нормі складає у невагітних жінок від 45 до $60 \%$ маси тіла, причому 2/3 її розташовується у внутрішньоклітинному секторі (ВКР) і 1/3 в позаклітинному (ПКР) (5\% - в судинах і $15 \%$ - в інтерстиції) [4]. Відносний вклад води в ГзМТ складає від 50 до 70 \%. Результати як більш ранніх, так і останніх досліджень демонструють, що істотне збільшення об'єму ЗВО і ПКР відбувається впродовж останніх двох триместрів вагітності. ВКР також змінюється і досягає максимального значення в кінці третього триместру $[5,6]$. Зміни ЗВО більшість науковців пояснюють затримкою води в молочних залозах, малому тазі та плазмі крові для забезпечення нормального перебігу пологів та післяпологового періоду. Вагітність також супроводжується збільшенням об'єму ПКР за рахунок зростання об'ємів амніотичної рідини, плазми крові у матері, інтерстиціальних набряків $[1,7]$.

Під час фрізіологічної вагітності відбувається розростання перисеричної судинної сітки. Як наслідок, зростають об'єм циркулюючої крові та серцевий викид для заповнення збільшеного судинного об'єму. Також зменшується загальний перифреричний опір судин за рахунок вазодилатації і внаслідок наявності низькоопірного шунта (плаценти), з наступним добре відомим загальним ефектом зниження артеріального тиску. Затримка рідини, 3 відповідним збільшенням 3ВО, відіграє важливе значення у зростанні об'єму плазми при прогресуванні вагітності. Цей механізм відіграє позитивну роль у плацентарно-плодовому кровотоці і знижує ризик «стресу зсуву напруги», уникаючи розвитку ендотеліального пошкодження [8].

Важливо визначити, оцінити і зрозуміти стан водних секторів організму на різних строках вагітності для отримання достовірної інфрормації про материнську адаптацію та/або дезадаптацію до вагітності. Існує декілька методів для вимірювання об'ємів рідинних просторів in vivo, однак не всі їх безпечно застосовувати під час вагітності [9]. Неінвазивні технології, такі як біоімпедансна спектроскопія або біоімпедансний аналіз (БІА), основані на електричній провідності біологічних тканин, дають можливість безпечно вимірювати активний і реактивний опір тіла людини та/або його сегментів. Субстратом активного опору є біологічні рідини (поза- та внутрішньоклітинні), які володіють іонним механізмом провідності. Значення активного опору, різні за частотою, є основою для оцінки 3ВО, безжирової м'язової маси, скелетно-м'язової маси та ПКР. 3 другого боку, реактивний опір створюють клітинні мембрани. За величиною їх реактивної складової додатково розраховують значення основного обміну та активної клітинної маси [10]. У численних зарубіжних публікаціях доведено безпечність застосування біоімпедансометрії (БІМ) у вагітних та точність і надійність проведення БІА складу тіла порівняно з еталонними методиками [6, 11, 12]. Практичне застосування БІА для оцінки компонентів складу тіла під час вагітності відображене в роботах Kent et al. при дослідженні зв'язку між об'ємом ЗВО і масою новонароджених [13], Gyselaers et al. та Staelens et al., при гіпертензивних розладах, прееклампсії та затримці розвитку плода [6, 14], a Strain et al. при ожирінні [15]. Проте, в літературі ми не знайшли даних про аналіз змін водного балансу організму в жінок з патологічним гестаційним приростом маси.

МЕТА ДОСЛІДЖЕННЯ - встановити ДИнаміку водних секторів у материнському організмі (об'єм ЗВО, ВКР та ПКР) під час вагітності у жінок з рекомендованим та патологічним ГЗМТ.

МАТЕРІАЛИ ТА МЕТОДИ. У дане проспектИвне дослідження було включено 153 вагітні жінки, які відвідували жіночі консультації м. Івано-Франківська за період 2016-2018 років. Критеріями виключення пацієнток із дослідження були вік до 18 років, багатоплідна вагітність, пологи до 37 тижнів, наявність тяжких хронічних соматичних захворювань. Дизайн проведеної роботи схвалений комісією з питань етики Івано-Франківського національного медичного університету (протокол № 93/16 від 01.12.2016 р.). Всі вагітні оформили «Інфрормовану згоду на участь в дослідженні».

$93(60,8 \pm 3,9$ \%) жінки були першонароджуючими і $62(40,5 \pm 4,0 \%)-3$ повторними пологами. Середній вік пацієнток становив $(28,3 \pm 5,1)$ року $(95 \%$ Cl 27,5-29,1). Середній зріст був $(165,1 \pm 5,2)$ см $(95 \%$ Cl 164,3-165,9), маса тіла до вагітності $(55,3 \pm 4,9)$ кг (95 \% Cl 54,5-56,1), прегравідарний індекс маси тіла (IMT) - $(20,3 \pm 1,5)$ кг/M² (95 \% Cl 20,1-20,5), що відповідало нормальній масі згідно з рекомендаціями Інституту медицини (США) та наказом МО3 України № $417[2,16]$. Рекомендоване

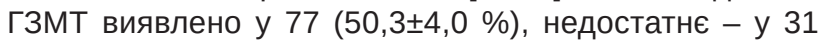
$(20,3 \pm 3,2 \%)$, а надлишкове у $45(29,4 \pm 3,7 \%)$ пацієнток, згідно з національними та міжнародними протоколами $[2,16]$. Взяття на облік в жіночу консультацію складало в середньому $(9,8 \pm 1,4)$ тижнів, пологи у всіх відбулися при доношеній вагітності ((39,1土1,3) тижнів).

Обстеження жінок проводили в 9-11, в 22-24 і в 37-39 тижнів вагітності. Вимірювали масу тіла пацієнток на електронних вагах, зріст за допомогою ростоміра, обвід 
талії та стегон - сантиметровою стрічкою. ІМТ розраховували за формулою Кетле: відношення маси тіла (кг) до квадрату зросту (м²) [18]. Інсрормацію про масу тіла жінок до вагітності отримували при опитуванні пацієнток та $з$ медичної документації. ГЗМТ оцінювали в кожному триместрі та в цілому за вагітність. Об'єм ЗВО, ПКР та їх відсотки, ВКР визначали на основі спектральної біоімпедансометрії (аналізатор «Диамант-аист») [17]. Ведення вагітності із рекомендаціями щодо харчування і фрізичної активності проводили згідно з національними нормативними документами [16].

Результати обробляли статистично з використанням пакета статистичного аналізу на базі Microsoft Excel та ліцензійного пакета програми «Statistica 6,0».

РЕЗУЛЬТАТИ ДОСЛІДЖЕННЯ ТА ЇХ ОБГОВОРЕННЯ. У зведеній таблиці 1 ми продемонстрували динаміку об'єму рідинних секторів у вагітних залежно від гестаційного приросту маси.

Так, у групі жінок із нормальним ГЗМТ відбулося достовірне зростання ЗВО з першого до другого триместру $(p<0,05)$ та, особливо, з другого до третього $(p<0,01)$. У кінці вагітності ЗВО в 1,3 раза $(p<0,001)$ та відсоток 3ВО в 1,1 раза $(p<0,01)$ вірогідно перевищували дані показники в ранні терміни. Встановлено, що ВКР та ПКР впродовж гестаційного періоду поступово наростали і перед пологами достовірно були вищими порівняно з першим триместром (відповідно, p<0,02 і р<0,05). Ми звернули увагу на відсутність статистично достовірних змін у відсотку ПКР $(p>0,05)$ та збереження співвідношення
ПКР/3ВО 0,35 у всіх триместрах, що незначно відрізняється від рефрерентних значень невагітних жінок (ПКР/ ЗВО 0,33) [17]. Це вказує на рівномірне зростання всіх рідинних секторів в організмі жінок при фрізіологічному перебігу вагітності.

В осіб з недостатнім ГЗМТ ми виявили достовірне зростання об'єму ЗВО $(p<0,01)$ та її відсоток $(p<0,05) 3$ першого триместру до кінця вагітності. Однак відмічено, що об'єм ЗВО був достовірно нижчий у всіх триместрах ( $p<0,05, p<0,05, p<0,01$ відповідно), починаючи вже з ранніх термінів, при відсутності статистично достовірної різниці його відсотка впродовж гестаційного періоду $(p>0,05)$ порівняно з групою жінок із нормальною надбавкою у масі. У цій групі виявлено відсутність динаміки відсотка ПКР та стабільний об'єм ВКР, збереження співвідношення ПКР/3ВО 0,34-0,33 у всіх триместрах.

У жінок із надлишковим ГЗМТ ми відмітили достовірне зростання 3ВО в 1,5 раза в третьому триместрі порівняно з першим і в 1,3 раза порівняно з другим (в обох випадках $\mathrm{p}<0,001)$. Відсоток ЗВО перед пологами також був вищим порівняно з ранніми термінами - $(66,0 \pm 1,1)$ проти $(58,5 \pm 1,0)(p<0,001)$ та порівняно з даним показником у групі з рекомендованим ГЗМТ $(p<0,05)$. Об'єм ВКР достовірно збільшувався протягом гестаційного періоду і в кінці вагітності перевищував параметри в першому та другому триместрах, відповідно, в 1,4 раза ( $>>0,002)$ та в $1,3$ раза ( $>>0,01)$. Проте найсуттєвіші зміни ми відмітили у динаміці ПКР. Так, вже в першому триместрі вагітності відсоток ПКР вірогідно був вищим порівняно з групою

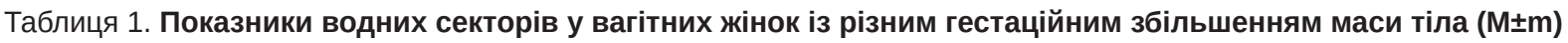

\begin{tabular}{|c|c|c|c|}
\hline \multirow{2}{*}{ Показники складу тіла } & \multicolumn{3}{|c|}{ Гестаційне збільшення маси тіла $(n=153)$} \\
\hline & нормальне $(n=77)$ & недостатнє $(\mathrm{n}=31)$ & надлишкове $(n=45)$ \\
\hline $\begin{array}{l}\text { Маса впродовж вагітності, кг } \\
\text { - I триместр } \\
\text { - II триместр } \\
\text { - III триместр }\end{array}$ & $\begin{array}{l}56,3 \pm 4,0 \\
61,4 \pm 4,1 \\
67,8 \pm 4,2\end{array}$ & $\begin{array}{l}54,2 \pm 4,3 \\
57,6 \pm 4,7 \\
62,0 \pm 5,4\end{array}$ & $\begin{array}{l}57,9 \pm 6,1 \\
65,6 \pm 6,1 \\
75,5 \pm 6,3\end{array}$ \\
\hline $\begin{array}{l}\text { 3ВО, л } \\
\text { - I триместр } \\
\text { - II триместр } \\
\text { - III триместр }\end{array}$ & $\begin{array}{c}33,3 \pm 1,2 \\
36,7 \pm 1,2^{\star} \\
42,6 \pm 1,6^{* *}\end{array}$ & $\begin{array}{l}30,0 \pm 1,1^{\circ} \\
32,4 \pm 1,3^{\circ} \\
36,5 \pm 1,7^{\star \circ}\end{array}$ & $\begin{array}{c}33,9 \pm 2,5 \\
39,4 \pm 1,6 \\
49,9 \pm 2,3^{*} * \star\end{array}$ \\
\hline $\begin{array}{l}\text { \% } 3 \text { ЗОО } \\
\text { - I триместр } \\
\text { - II триместр } \\
\text { - III триместр }\end{array}$ & $\begin{array}{l}59,1 \pm 1,1 \\
59,8 \pm 1,0 \\
62,8 \pm 1,2^{\star}\end{array}$ & $\begin{array}{l}56,0 \pm 1,3 \\
56,4 \pm 1,4 \\
58,9 \pm 1,4^{\star}\end{array}$ & $\begin{array}{c}58,5 \pm 1,0 \\
60,0 \pm 1,1 \\
66,1 \pm 1,1^{* * *}\end{array}$ \\
\hline $\begin{array}{l}\text { ВКР, л } \\
\text { - I триместр } \\
\text { - II триместр } \\
\text { - III триместр }\end{array}$ & $\begin{array}{l}21,6 \pm 1,4 \\
23,6 \pm 2,0 \\
27,4 \pm 1,8^{\star}\end{array}$ & $\begin{array}{l}19,8 \pm 1,4 \\
21,3 \pm 1,4 \\
24,4 \pm 1,5\end{array}$ & $\begin{array}{c}20,6 \pm 1.4 \\
21.9 \pm 1,3 \\
28,0 \pm 1,7^{* \star \star}\end{array}$ \\
\hline $\begin{array}{l}\text { ПКР, л } \\
\text { - I триместр } \\
\text { - II триместр } \\
\text { - III триместр }\end{array}$ & $\begin{array}{c}11,7 \pm 1,1 \\
13,1 \pm 1,1 \\
15,2 \pm 1,2^{\star}\end{array}$ & $\begin{array}{l}10,2 \pm 1,0 \\
11,1 \pm 1,3 \\
12,1 \pm 1,6\end{array}$ & $\begin{array}{c}13,3 \pm 1,1 \\
16,8 \pm 1,3^{\star \circ} \\
21,9 \pm 1,8^{* \star *}\end{array}$ \\
\hline $\begin{array}{l}\text { \% ПКР } \\
\text { - I триместр } \\
\text { - II триместр } \\
\text { - III триместр }\end{array}$ & $\begin{array}{l}35,1 \pm 0,9 \\
35,6 \pm 0,9 \\
35,6 \pm 0,9\end{array}$ & $\begin{array}{l}34,0 \pm 1,0 \\
34,3 \pm 1,1 \\
33,1 \pm 1,1\end{array}$ & $\begin{array}{l}39.2 \pm 1,0^{\circ} \\
42,6 \pm 1,1^{*} \circ \\
43,8 \pm 1,2^{\star}\end{array}$ \\
\hline
\end{tabular}

Примітка. * - p<0,05 при порівнянні показників із І триместром вагітності; ** - p<0,05 при порівнянні показників із ІІ триместром вагітності; ${ }^{\circ}-$ p<0,05 при порівнянні показників у жінок із нормальним ГЗМТ. 
жінок із нормальним ГЗМТ (p>0,01), і така тенденція мала місце до кінця вагітності ( $p<0,01)$. Ми прослідкували, що співвідношення ПКР/3ВО було 0,39, 0,43 і 0,44 відповідно в кожному триместрі вагітності. Отже, у групі вагітних із надлишковим гестаційним приростом маси порівняно 3 рекомендованою надбавкою в масі продемонстровано надмірне зростання ЗВО, ПКР та їх відсотка, починаючи з ранніх строків, із максимальними значеннями цих показників у кінці вагітності.

У нашій роботі за результатами спектральної біоімпедансометрії підтверджено, що рівномірне наростання 3ВО на 30,0 \% та всіх водних секторів до кінця гестаційного періоду і збереження співвідношення між внутрішньоклітинним та позаклітинним компонентами забезпечує гестаційний приріст маси в рекомендованих межах, що висвітлено і в інших дослідженнях $[5,6]$. Зниження накопичення загальної рідини організму при збереженні нормального відсотка 3ВО та відсутності дисбалансу між компонентами, за нашими даними, може бути пов'язано з недостатнім надходженням нутритивних речовин та води з харчуванням і відіграє значну роль у недостатньому ГЗМТ. Суттєві водно-секторальні зрушення у вигляді аномальної затримки рідини, в основному за рахунок ПКР, починаючи вже з першого триместру вагітності, приводять до патологічного ГЗМТ і є ризиком акушерських та перинатальних ускладнень, пов'язаних із гемодинамічними розладами.

ВИСНОВКИ. Продемонстровано доцільність використання спектральної біоімпедансометрії для моніторингу динаміки водних секторів у вагітних жінок, починаючи 3 першого триместру, з метою раннього виявлення неадекватної затримки та перерозподілу рідинних компонентів, що приводить до патологічного ГЗМТ і $є$ проявом гемодинамічної дезадаптації до вагітності.

ПЕРСПЕКТИВИ ПОДАЛЬШИХ ДОСЛІДЖЕНЬ ПОлягають у вивченні ролі водно-секторальних порушень у розвитку акушерських та перинатальних ускладнень 3 метою розробки методів профілактичної терапії.

\section{СПИСОК ЛІТЕРАТУРИ}

1. Body composition during normal pregnancy: reference ranges / G. Larciprete, H. Valensise, B. Vasapollo [et al.] // Acta Diabetol. - 2003. - Vol. 40 (Suppl. 1). - P. 225-232.

2. ACOG, Weight gain during pregnancy. Committee Opinion No. 548. American College of Obstretricians and Gynecologists // Obstet. Gynecol. - 2013. - No. 121. - P. 210-215.

3. Bioelectrical impedance analysis in pregnancy: reference ranges in / S. Berlit, B. Tuschy, M. Stojakowits, [et al.] // Vivo. 2013. - 27. - P. 851-854.

4. Total body water reference values and prediction equations for adults / W. C. Chumlea, S. S. Guo, C. M. Zeller [et al.] // Kidney international. - 2001. - Vol. 59 (6). - P. 2250-2258.

5. Bioimpedance in pregnant women with Preeclampsia / E. Gomes da Silva, M. A. Carvalhaes, H. S. Hirakawa [et al.] // Hypertension in Pregnancy. - 2010. - Vol. 29. - P. 357-365.

6. Body fluid volume homeostasis is abnormal in pregnancies complicated with hypertension and/or poor fetal growth / W. Gyselaers, S. Vonck, A. S. Staelens [et al.] // PLoS One. 2018. - Vol. 13 (11).

7. Bioelectrical impedance among rural Bangladeshi Women during pregnancy and in the postpartum period / S. Shaikh, K. J. Schulze, H. Ali [et al.] // Journal of Health, Population, and Nutrition. - 2011. - Vol. 29. - P. 236-244.

8. Physiological changes in pregnancy / P. Soma-Pillay, C. Nelson-Piercy, H. Tolppanen [et al.] // Cardiovasc. J. Afr. 2016. - Vol. 27 (2). - P. 89-94.

9. Биоимпедансометрия как метод оценки компонентного состава тела человека : обзор литературы / И. В. Гайворонский, Г. И. Ничипорук, И. Н. Гайворонский [и др.] // Вестник Санкт-Петербургского университета. - М. : Медицина. - 2017. - T. 12 (4). - C. 365-384.

10. The theory and fundamentals of bioimpedance analysis in clinical status monitoring and diagnosis of diseases / F. Kh. Sami, S. M. Mas, I. Fatimah // Sensors (Basel). - 2014. - Vol. 14 (6). - P. 10895-10928.

11. Bioimpedance at the bedside: current applications, limitations, and opportunities / U. Mulasi, A. J. Kuchnia, A. J. Cole [et al.] // Nutr. Clin. Pract. - 2015. - Vol. 30 (2). - P. 180-193.

12. Classification of hydration in clinical conditions: Indirect and direct approaches using bioimpedance / H. C. Lukaski, D. N. Vega, A. Talluri [et al.] // Nutrients. - 2019. - Vol. 11 (4).

13. Correlation between birth weight and maternal body composition / E. Kent, V. O'Dwyer, C. Fattah [et al.] /I Obstetrics and Gynecology. - 2013. - Vol. 121 (1). - P. 46-50.

14. Maternal body fluid composition in uncomplicated pregnancies and preeclampsia: a bioelectrical impedance analysis / A. S. Staelens, S. Vonck, G. Molenberghs [et al.] // European Journal of Obstetrics, Gynecology, and Reproductive Biology. - 2016. - Vol. 204. P. 69-73.

15. Bioimpedance for severe obesity: comparing research methods for total body water and resting energy expenditure / G. W. Strain, J. Wang, M. Gagner [et al.] // Obesity. - 2008. Vol. 16 (8). - P. 1953-1956.

16. Наказ МОЗ України № 417 від 15.07.2011 «Методичні рекомендації щодо організації надання амбулаторної акушерсько-гінекологічної допомоги». - Київ.

17. Николаев Д. В. Биоимпедансный анализ состава тела человека / Д. В. Николаев, А.В.Смирнов, И.Г.Бобринская, С. Г. Руднев. - М. : Наука, 2009. - 392 с.

18. Жулкевич І. В. Персоналізація в онкології: індивідуальний підхід до профрілактики тромбоемболічних ускладнень при пангістеректомії / І. В. Жулкевич, Б. Д. Кривокульський // Вісник соціальної гігієни та організації охорони здоров'я України. - 2018. - № 4. - С. 11-18.

\section{REFERENCES}

1. Larciprete, G., Valensise, H., Vasapollo, B., Altomare, F., Sorge, R., Casalino, B. ..., \& Arduini, D. (2003). Body composition during normal pregnancy: reference ranges. Acta Diabetol., 40 (Suppl. 1), 225-232. DOI:10.1007/s00592-003-0072-4.

2. ACOG (2013). Weight gain during pregnancy. Committee Opinion No. 548. American College of Obstretricians and Gyne- cologist. Obstet. Gynecol., 121, 210-215. DOI: http://10.1097/01. AOG.0000425668.87506.4c

3. Berlit, S., Tuschy, B., Stojakowits M., Weiss, C., Leweling, H., Suttrlin, M., \& Kehl, S. (2013). Bioelectrical Impedance Analysis in Pregnancy: Reference Rangesin. In Vivo, 27, 851-854. Retrieved from: http://iv.iiarjournals.org/content/27/6/851.full.pdf 
4. Chumlea, W.C., Guo, S.S., Zeller, C.M., Reo, N.V., Baumgartner, R.N., \& Garry, P.J. (2001). Total body water reference values and prediction equations for adults. Kidney International, 59 (6), 2250-2258. DOI:10.1046/j.15231755.2001.00741.x PMID: 11380828.

5. Gomes da Silva, E., Carvalhaes, M.A., Hirakawa, H.S., Guimarães da Silva, E. \& Peraçoli, J.C. (2010). Bioimpedance in pregnant women with preeclampsia. Hypertension in Pregnancy, 29, 357-365. DOI: 10.3109/10641950903116523.

6. Gyselaers, W., Vonck, S., Staelens, A. S., Lanssens, D., Tomsin, K., Oben, J., ..., \& Bruckers, L. (2018). Body fluid volume homeostasis is abnormal in pregnancies complicated with hypertension and/or poor fetal growth. PLoS One, 13(11). DOI: 10.1371/journal.pone.0206257.

7. Shaikh, S., Schulze, K.J., Ali, H., Labrique, A.B., Shamim, A.A., Rashid, M., ..., \& West, K.P. (2011). Bioelectrical impedance among rural Bangladeshi Women during pregnancy and in the postpartum period. Journal of Health, Population, and Nutrition, 29, 236-244.

8. Soma-Pillay, P., Nelson-Piercy, C., Tolppanen, H., \& Mebazaa, A. (2016). Physiological changes in pregnancy. Cardiovasc. J. Afr., 27 (2), 89-94. DOI: 10.5830/CVJA-2016-021.

9. Gaivoronskiy, I.V., Nichiporuk, G.I., Gaivoronskiy, I.N \& Nichiporuk, N.G. (2017). Bioimpedansomertia kak metod otsenki komponentnogo sostava tela cheloveka [Bioimpedansometry as a method of the component body structure assessment (revier)]. Vestnik of Saint Petersburg University, Meditsina - Bulletin of St. Petersburg University. Medicine, 12 (4), 365-384 [in Russian].

10. Sami, F.Kh., Mas, S.M., \& Fatimah, I. (2014). The Theory and fundamentals of bioimpedance analysis in clinical status monitoring and diagnosis of diseases. Sensors (Basel), 14 (6), 10895-10928. DOI: 10.3390/s140610895.

11. Mulasi, U., Kuchnia, A.J., Cole, A.J., \& Earthman, C.P. (2015). Bioimpedance at the bedside: current applications, limitations, and opportunities. Nutr. Clin. Pract., 30(2), 180-193. DOI: 10.1177/0884533614568155

12. Lukaski, H.C., Vega, D.N., Talluri, A., \&Nescolarde, L.
(2019). Classification of hydration in clinical conditions: Indirect and direct approaches using bioimpedance. Nutrients., 11 (4), 809. DOI: $10.3390 /$ nu11040809.

13. Kent, E., O'Dwyer, V., Fattah, C., Farah, N., O'Connor, C., \& Turner, M.J. (2013) Correlation between birth weight and maternal body composition. Obstetrics and Gynecology, 121 (1), 46-50. DOI.://10.1097/AOG.0b013e31827a0052

14. Staelens, A.S., Vonck, S., Molenberghs, G., Malbrain, M.L., \& Gyselaers, W. (2016). Maternal body fluid composition in uncomplicated pregnancies and preeclampsia: a bioelectrical impedance analysis. European Journal of Obstetrics, Gynecology, and Reproductive Biology, 204, 69-73.

DOI.org/10.1016/j.ejogrb.2016.07.502 PMID: 2752568321.

15. Strain, G.W., Wang, J., Gagner, M., Pomp, A., Inabnet, W.B., \& Heymsfield, S.B. Bioimpedance for severe obesity: comparing research methods for total body water and resting energy expenditure. Obesity, 16 (8), 1953-1959. DOI:10.1038/ oby.2008.321.

16. Nakaz Ministerstva okhorony zdorovia Ukrainy "Metodychni rekomendatsii shchodo orhanizatsii ambulatornoi akushersko-ginekolohichnoi dopomohy" vid 15.07.2011 r. № 417 [Order of the Ministry of Health of Ukraine «Methodological recommendations for the organization of ambulatory obstetric and gynecological care» from July 15, 2011 № 417]. Kyiv [in Ukrainian]. Retrieved from: https://z-I.com.ua/upload//moz\% 20docs/417.pdf.

17. Nikolaev, D.V., Smirnov, A.V., Bobrinskaya, I.G., \& Rudnev, S.G. (2009). Bioimpedansny analiz sostava tela cheloveka [Bioelectric impedance analysis of human body composition]. Moscow: Nauka [in Russian].

18. Zhulkevych, I.V., \& Kryvokulskyi, B.D. (2018). Personalizatsiia v onkolohii: indyvidualnyi pidkhid do profilaktyky tromboembolichnykh uskladnen pry panhisterektomii [Personalization in oncology: individual approach to the prevention of thromboembolic complications during hysterectomy]. Visnyk sotsialnoi hihiieny ta orhanizatsii okhorony zdorovia Ukrainy - Bulletin of Social Hygiene and Health Protection Organization of Ukraine, 4, 11-18 [in Ukrainian]. 